\title{
Are we Giving Sufficient Protein in Parenteral Nutrition Support? A Cross-sectional Study on Adult Patients in Intensive Care Units
}

\author{
Pui Wun Fiona Fong*, Mahmud Majdi bin Mahmud Saedon, Stella Caroline J Bangguan \\ Department of Pharmacy, Hospital Queen Elizabeth II, Kota Kinabalu, Sabah, MALAYSIA
}

Received: 11 May 2021;

Accepted: 28 June 2021

*Correspondence to:

Pui Wun Fiona Fong,

Department of Pharmacy, Hospital Queen Elizabeth II, Kota Kinabalu, Sabah, MALAYSIA. Phone no: $+6088-324600$ Email: fiona fong0402@yahoo.com Copyright: (C) the author(s),publisher and licensee Indian Academy of Pharmacists. This is an open-access article distributed under the terms of the Creative Commons Attribution Non-Commercial License, which permits unrestricted non-commercial use, distribution, and reproduction in any medium, provided the original work is properly cited.

\begin{abstract}
Protein plays a significant role in nutritional support, especially for patients at intensive care unit (ICU) who commonly suffer from net loss of protein. ASPEN and ESPEN guidelines recommend a minimum protein of $1.2 \mathrm{~g} / \mathrm{kg} /$ day for ICU patients; Kidney Disease: Improving Global Outcomes (KDIGO) recommends 0.8g/ $\mathrm{kg} /$ day for chronic kidney disease (CKD) stage 4 to 5 . This study aimed to determine whether adequate protein was given to adult ICU patients and identify the factors for discrepancy in local settings. A crosssectional study including all adult ICU patients receiving parenteral nutrition (PN) in Hospital Queen Elizabeth (HQE) and HQE II was conducted from January 2018 to April 2019. Relevant information was obtained from patients' pharmacotherapy review forms. For patients receiving PN and enteral nutrition (EN) concurrently, protein from both sources was accounted for. Among the 52 patients, majority were male $(n=41 ; 78.8 \%)$ with median age of 52 years old $(I Q R=34.5)$. Median duration of PN support was 6 days $(I Q R=6.3)$, and gastrointestinal perforation was the most common indication $(n=11 ; 21.2 \%)$. All 45 non-CKD patients (86.5\%) received minimum recommended protein of $1.2 \mathrm{~g} / \mathrm{kg} / \mathrm{day}$. Ten patients $(19.2 \%$ out of 52$)$ who received PN and EN concurrently received a higher average protein up to $1.5 \mathrm{~g} / \mathrm{kg} / \mathrm{day}$. Out of 7 patients $(13.5 \%)$ with underlying CKD stage 4 to 5 , two (3.8\% of total 52 patients) received insufficient protein below $0.8 \mathrm{~g} / \mathrm{kg} /$ day due to restriction of fluid (ROF). Majority of the patients received sufficient protein as per guidelines. In real-life practice, discrepancy may occur due to the fixed-content formulations of commercial PN bags.
\end{abstract}

Key words: Protein, Adult, Parenteral Nutrition, Nutrition Support, Intensive Care Unit.

\section{INTRODUCTION}

Parenteral Nutrition (PN) refers to the intravenous administration of nutrients, which include amino acids (AA), dextrose, lipids, electrolytes, micronutrients and fluids..$^{[1,2]}$ It is indicated for patients with conditions that partially or entirely impair oral and enteral feeding. ${ }^{[3,4]} \mathrm{PN}$ was developed in 1968 and has since then been widely adopted, including for critically ill patients in Intensive Care Unit (ICU) setting. ${ }^{[4]}$ Concurrently, the progressive and rapid loss of body mass and muscle among patients with critical illness, also known as hyper metabolism, was well recognized. ${ }^{[4]}$ However, due to the previous misconception that critically ill patients have very high energy expenditure, focus was on energy intake instead of adequate protein intake..$^{[4]}$ It was only in the recent decades that the significance of protein in critically ill patients was acknowledged and widely studied on.

Unlike glucose and fatty acids which can be stored as glycogen and triglycerides respectively, amino acids and protein cannot be stored as reservoir in the body. ${ }^{[5,6]}$ Thus, dietary amino acids must be incorporated into functional proteins in order to be preserved from oxidation. Insufficient protein intake may lead to negative protein balance and therefore skeletal muscle atrophy, impaired muscle growth and ultimately functional decline. ${ }^{[4,6]}$ This is especially important for ICU patients who are in hypercatabolic state due to a combination of several reasons. Firstly, diseases and conditions such as sepsis, trauma or respiratory failure, alongside comorbidities such as diabetes and coronary artery disease (CAD), often carry a high degree of inflammation. ${ }^{[6]}$ This stimulates the release of AA from muscles into bloodstream, which are then taken up by liver and other tissues to be synthesized into acutephase proteins involved in regulating the immunoinflammatory processes. ${ }^{[7]}$ Secondly, bed rest inactivity may provoke anabolic resistance, limiting the amount of exogenous AA that can be incorporated to the endogenous protein. ${ }^{[7]}$ One of the mechanisms of this anabolic resistance is insulin resistance, which limits AA uptake into muscles and speeds up proteolysis. ${ }^{[7,8]}$ These, overall, result in net protein loss due to increased catabolism and decreased anabolism.

Several recent studies demonstrated an association between adequate protein intake (i.e. at least 1.2 to $1.5 \mathrm{~g} / \mathrm{kg} /$ day) and improved clinical outcomes in critically ill patients. ${ }^{[1,9]}$ This target coincides with the European Society for Clinical Nutrition and Metabolism (ESPEN) guideline 2009 on clinical nutrition in the intensive care unit. ${ }^{[1]}$ Minimum protein target as per American Society for Parenteral and Enteral Nutrition (ASPEN) is also $1.2 \mathrm{~g} / \mathrm{kg} /$ day. ${ }^{[10]}$ However, for patients with chronic kidney disease (CKD) stage 4 to 5 , which is defined as glomerular filtration rate (GFR) lower than $30 \mathrm{~mL} /$ $\mathrm{min} / 1.73 \mathrm{~m}^{2}$, Kidney Disease: Improving Global Outcomes (KDIGO) guidelines recommend that protein intake should be reduced to $0.8 \mathrm{~g} / \mathrm{kg} /$ day. ${ }^{[1]}$ Hence in this study, the recommended protein requirement and the term "sufficient protein" would be defined as $1.2 \mathrm{~g} / \mathrm{kg} /$ day for patients without CKD stage 4 to 5 , or otherwise $0.8 \mathrm{~g} / \mathrm{kg} /$ day. For patients with concurrent oral or enteral feeding, amount of protein from this feeding would be included into the calculation of the total amount of protein received by patients.

Regardless of these recommendations, current observational studies found that critically ill patients are receiving less than half of these recommendations. ${ }^{[1,10]}$ There is also a lack of studies in Malaysia to review the amount of contents in PN bags received by patients against the recommended targets. In view of the importance of proteins particularly in critically ill adult patients, this study plays a significant role in examining the amount of proteins received by adult 
ICU patients from PN support at local facilities to assess any discrepancy and necessary improvement.

\section{MATERIALS AND METHODS Study Design}

This was a multicenter cross-sectional study involving all adult ICU patients receiving PN in HQE and HQE II from January 2018 to April 2019. The pharmacotherapy review forms, which were developed by the Health Ministry of Malaysia and adopted by HQE II Total Parenteral Nutrition (TPN) department, of all selected patients were reviewed. These forms contained information on patients' personal details, past medical and medication histories, diagnosis, indication for $\mathrm{PN}$, lab investigation results, daily progress on feeding and fluid input and output, plans by doctors and/or specialists, as well as daily PN regime. Information and study parameters from the forms will be tabulated in a Data Collection Form, including: (1) patient's gender, (2) patient's age in years, (3) ward, (4) body weight (BW) for calculation in $\mathrm{kg}$, (5) indication for PN, (6) day of PN, (7) concurrent oral/enteral feeding, (8) type of PN bag, (9) amount of protein in PN bag in gram (g), (10) amount of additional protein (e.g. Aminoven/glutamine/protein from oral or enteral feeding) in g, (11) total amount of protein supplied per BW ( $\mathrm{g} / \mathrm{kg} /$ day) and (12) presence of underlying CKD stage 4 or 5.

Admission BW and height were used to calculate individual patient's body mass index (BMI), with formula BMI $=\mathrm{BW} /$ height $^{2}\left(\mathrm{~kg} / \mathrm{m}^{2}\right)$. If actual BW was infeasible due to reasons such as inability to stand, the best clinical estimate was obtained from care providers. BMI was then categorized into underweight $\left(<18.5 \mathrm{~kg} / \mathrm{m}^{2}\right)$, normal weight $\left(18.5\right.$ to $\left.<25.0 \mathrm{~kg} / \mathrm{m}^{2}\right)$, overweight $\left(25.0\right.$ to $\left.<30.0 \mathrm{~kg} / \mathrm{m}^{2}\right)$ and obese $\left(>30.0 \mathrm{~kg} / \mathrm{m}^{2}\right)$, as per recommendation by World Health Organization (WHO) and Centers for Disease Control and Prevention (CDC). ${ }^{[12,13]}$

There are several BW for calculation: actual BW (ABW), which is the weight measured or reported upon hospitalization ${ }^{1}$; ideal BW (IBW), which is the BW related to height, with formula $(160$ - 152.4) x $0.9+50$ for male and $(160-152.4) \times 0.9+45$ for female $;^{[14]}$ and adjusted BW (AjBW) with formula $\mathrm{IBW}+0.4 \times$ (Actual BW $-\mathrm{IBW}) \cdot{ }^{[15]}$ The choice of BW for calculation was determined from the BMI category: for underweight patients, BW for calculation was derived from $\mathrm{BMI}+2$; for normal weight patients, $\mathrm{ABW}$ was used; for overweight patients, $\mathrm{AjBW}$ was used; for obese patients, IBW was used.

\section{Study Population}

This study involved all patients who were admitted to ICU of any department in HQE and HQE II from January 2018 to April 2019, and received PN during hospitalization. Only patients of age 18 years old and above upon admission were included. Should patient be transferred to non-ICU ward any time during the admission, only the period of ICU stay was taken into account.

\section{Ethics, Privacy and Confidentiality}

This study was conducted in accordance to the ethical principles outlined in the Declaration of Helsinki and Malaysian Good Clinical Practice Guideline. The researchers applied for ethical approval from the National Medical Research and Ethic Committee (MREC) of the Ministry of Health (MOH), Malaysia via the National Medical Research Registry (NMRR) before the commencement of research.

No identifiable data was collected from the patients' medical histories. The data collection forms were kept by the investigators only for data analysis purpose. No personal information was disclosed during the communication between relevant departments. Individual subjects were not identified when publishing the survey outcomes.

\section{Study Analysis}

The data analysis was performed using SPSS version 17. Descriptive analysis was used to present the result in this study. Numerical data was presented in mean (standard deviation) or median (interquartile range) depending on data normality. Categorical data was presented as frequency and percentage.

\section{RESULTS \\ Patients' Baseline Characteristics}

A total of 52 patients at HQE and HQE II ICU received PN during the study period. Majority of the patients were male $(n=41 ; 78.8 \%)$ with median age of 52 years old and an interquartile range (IQR) of 34.5. Average BW for calculation was $57.9 \mathrm{~kg}$, with a standard deviation (SD) of $8.0 \mathrm{~kg}$. PN support was received for a range of 1 to 23 days, and a median duration of 6 days (IQR $=6.3$ ), with only duration in ICU taken into account. Of the 52 patients, $7(13.5 \%)$ presented with underlying CKD stage 4 or 5 . Gastrointestinal perforation was the most common indication for PN, comprising 11 out of the 52 cases, equivalent to $21.2 \%$. The patients' baseline characteristics are summarized in Table 1.

\section{Daily Protein Intake during ICU Stay}

For the 45 non-CKD patients (86.5\%), all received minimum recommended protein of $1.2 \mathrm{~g} / \mathrm{kg} / \mathrm{day}$. Among these patients, on top of the protein content in PN bag, 15 patients (28.8\% out of total 52) received additional protein from glutamine added into PN bag with aseptic techniques, or Aminoven $10 \%$ in an intravenous piggyback. Ten $(19.2 \%$ out of 52$)$ received PN and enteral nutrition (EN) concurrently with a higher average protein intake up to $1.5 \mathrm{~g} / \mathrm{kg} /$ day.

Out of the 7 patients $(13.5 \%)$ with underlying CKD stage 4 to 5 , two patients $(3.9 \%$ of total 52 patients) received insufficient protein below $0.8 \mathrm{~g} / \mathrm{kg} / \mathrm{day}$, ranging from 0.5 to $0.6 \mathrm{~g} / \mathrm{kg} /$ day.

Commercial all-in-one (AIO) PN bags with fixed formulations were used throughout ICU admission, except for 3 patients (5.8\%) who were switched halfway from commercial bags to individually customized regimens prepared by pharmacy, with reasons of ROF or the need for electrolyte adjustment. The results are tabulated in Table 2.

\section{DISCUSSION}

The topic of adequate protein supply to in-ward patients especially at ICU settings has been in debate for decades. Various studies have been conducted with conflicting results. Large multicenter observational studies demonstrated beneficial outcomes of higher protein intake on mortality reduction and survival improvement, which included a study prescribing protein of 1.2$1.5 \mathrm{~g} / \mathrm{kg} /$ day. ${ }^{[16]}$ In contrast, randomized controlled trials (RCTs) did not observe significant clinical differences with higher protein delivery, and were less conclusive on the optimal protein requirement. ${ }^{[1,17]}$ However, large heterogeneity was found among these RCTs in terms of sample size, selected patient population, protein dose prescribed and clinical endpoints. Therefore, guidelines on nutrition support for critically ill patients, including ASPEN and ESPEN, were based on the observational studies available, with $1.2 \mathrm{~g} / \mathrm{kg} /$ day as minimum protein target for ICU patients without CKD complication. 
Table 1: Baseline Characteristics of Patients $(n=52)$.

\begin{tabular}{|l|l|l|l|}
\hline Variable & $\mathbf{n}(\%)$ & $\begin{array}{l}\text { Mean } \\
\text { (SD) }\end{array}$ & $\begin{array}{l}\text { Median } \\
\text { (IQR) }\end{array}$ \\
\hline Gender & $41(78.8)$ & & \\
\hline Male & $11(21.2)$ & & \\
\hline Female & & & $52(34.5)$ \\
\hline Age (years) & & $57.9(8.0)$ & \\
\hline Body weight for calculation (kg) & & & $6(6.3)$ \\
\hline Duration of PN support & & & \\
\hline Ward & $39(75.0)$ & & \\
\hline General ICU HQE & $9(17.3)$ & & \\
\hline General ICU HQE II & $4(7.7)$ & & \\
\hline Cardiothoracic ICU HQE II & $7(13.5)$ & & \\
\hline $\begin{array}{l}\text { Presence of underlying CKD stage } \mathbf{5} \\
\text { Indication for PN }\end{array}$ & & & \\
\hline Gastrointestinal perforation & $11(21.2)$ & & \\
\hline Gastrointestinal tumour & $7(13.5)$ & & \\
\hline Polytrauma secondary to MVA & $6(11.5)$ & & \\
\hline Paralytic/septic ileus & $6(11.5)$ & & \\
\hline Gastrointestinal bleeding & $5(9.6)$ & & \\
\hline Anastomotic leak & $4(7.7)$ & & \\
\hline Fistula & $4(7.7)$ & & \\
\hline Bowel ischemia & $4(7.7)$ & & \\
\hline Feeding intolerance & $3(5.8)$ & & \\
\hline Bowel gangrene/necrosis & $2(3.8)$ & & \\
\hline SD-san & & \\
\hline & & & \\
\hline
\end{tabular}

SD- standard deviation; IQR- interquartile range; CKD- chronic kidney disease

For patients with $\mathrm{CKD}$, daily protein requirement may differ depending on the CKD stage and the presence of haemodialysis (HD) treatment. ESPEN and National Kidney Foundation (NKF) recommend a daily protein intake of $0.6-0.75 \mathrm{~g} / \mathrm{kg} /$ day for CKD stage 3-5 patients without HD treatment, and a higher target of $1.2 \mathrm{~g} / \mathrm{kg} /$ day for those on HD. ${ }^{[18]}$ This is because HD is a catabolic procedure per se, incurring greater energy expenditure among HD patients. ${ }^{[18]}$ Higher protein intake is also required to compensate for the protein losses of $10-15 \%$ from infused $\mathrm{PN}$ into the dialysate ${ }^{[18]}$ On the other hand, KDIGO recommends $0.8 \mathrm{~g} / \mathrm{kg} /$ day protein for CKD stage 4-5 without regards of HD. ${ }^{[1]}$ Due to the fact that all CKD patients in this study were at stage 4 without routine HD, KDIGO recommendation was adopted.

In this study, only 2 patients (3.9\%) with underlying CKD received insufficient protein below $0.8 \mathrm{~g} / \mathrm{kg} /$ day, ranging from 0.5 to $0.6 \mathrm{~g} / \mathrm{kg} /$ day. However, both of the cases presented with underlying restriction of fluid (ROF). With other concurrent medications requiring dilution without HD for fluid extraction, remaining volume available for $\mathrm{PN}$ was limited. This in turn limited the amount of contents able to be delivered to patients, including protein. Since the maximum amount of PN compositions is volume-dependent and directly affects the overall stability, even opting for customized regimen prepared by pharmacy may not be able to resolve the issue. Apart from ROF, customized regimens for 3 patients in this study were designed for the purpose of electrolyte adjustment, as 2 patient's required PN solution omitting sodium electrolyte following persistent hypernatremia. Therefore, the fact that almost all patients in our ICU settings received adequate protein from nutrition support demonstrated ideal practice as per guidelines.
Table 2: Average Daily Protein Intake during ICU Stay.

\begin{tabular}{|l|l|l|}
\hline & $\mathbf{n}(\%)$ \\
& $\begin{array}{l}\text { Non-CKD } \\
\text { patients }(\mathbf{n}=\mathbf{4 5}) \\
\text { Minimum } \\
\text { protein target } \\
\mathbf{1 . 2} \mathbf{~ g / k g / d a y}\end{array}$ & $\begin{array}{l}\text { CKD patients }(\mathbf{n}=7) \\
\text { Minimum protein } \\
\text { target } \\
\mathbf{0 . 8} \mathbf{g} / \mathbf{k g} / \text { day }\end{array}$ \\
\hline PN only & $20(44.4)$ & $7(100.0)$ \\
\hline PN + glutamine/Aminoven $10 \%$ & $15(33.3)$ & $0(0)$ \\
\hline PN + EN & $10(22.2)$ & $0(0)$ \\
\hline Commercial PN & $43(95.6)$ & $6(85.7)$ \\
\hline Customized regimen & $2(4.4)$ & $1(14.3)$ \\
\hline $\begin{array}{l}\text { Minimum protein target } \\
\text { achieved }\end{array}$ & $45(100.0)$ & $5(71.4)$ \\
\hline
\end{tabular}

ICU- intensive care unit; CKD- chronic kidney disease; PN- parenteral nutrition;

EN- enteral nutrition

In certain cases, energy and protein requirements may not change proportionately and should be considered separately. This is especially important for ICU patients who are prescribed with PN during the early phase of acute illness. ESPEN recommended that in the absence of indirect calorimetry, hypocaloric nutrition should be preferred over isocaloric nutrition for the first week of ICU admission, providing no more than $70 \%$ of the caloric requirement estimated from predictive equation. ${ }^{[1]}$ The rationale is to avoid overfeeding or refeeding but simultaneously ensuring sufficient precursors for acute phase proteins in response to immunoinflammatory processes. ${ }^{[1]}$ With fixed compositions of commercial PN bags, limiting calories is equivalent to limiting protein delivery. Therefore, products with a higher protein to energy ratio need to be considered.

While glutamine and Aminoven 10\% serve as additional source of amino acids, glutamine has been thought to have a significant role in critically ill patients. As opposed to Aminoven 10\% which comprises a range of essential and non-essential amino acids, glutamine is a specified type of conditionally essential amino acid during critical illness. ${ }^{[19]}$ Glutamine plays a role in modulating inflammatory and oxidative stress responses which are amplified in critically ill patients. The increased requirements for mechanisms such as immunomodulation, wound healing and gluconeogenesis may exceed the endogenous capacity for glutamine synthesis. An early response to such stress is a rapid release of muscle glutamine, followed by decrease in both muscle and plasma free glutamine concentrations. ${ }^{[20]}$ Consequently, there is an upregulation of muscle glutamine synthesis from amino acids derived from a net increase in muscle proteolysis. ${ }^{[20]}$ Hence exogenous supplementation of glutamine seems to be warranted for immunomodulatory responses and to prevent the loss of lean body muscle from proteolysis. However, evidence on the beneficial effects of glutamine has been controversial. While small single centre studies demonstrated a significant reduction in mortality and infectious morbidity with glutamine supplementation, the more recent large, multicenter studies did not confirm this finding. ${ }^{[1,20]}$ REDOXS study, being one of the large multicentre RCTs, showed deleterious effect on mortality among patients with multi-organ failure when given high dose of glutamine. ${ }^{[1,20]}$ Another RCT, Signet trial, did not demonstrate significant difference in patient group receiving glutamine of $20.2 \mathrm{~g} /$ day, which falls within the recommended dose of $0.3-0.6 \mathrm{~g} / \mathrm{kg} /$ day for a standard-sized patient weighed approximately $60 \mathrm{~kg} \cdot{ }^{\left[{ }^{[20]}\right.}$ Hence to date, no conclusive result can be drawn from addition of glutamine to critically ill patients, except that it shall not be given to unstable patients particularly those with renal and liver failure. ${ }^{[1]}$ 


\section{Limitations}

Sufficient delivery of protein or even positive nitrogen balance does not necessarily translate into positive clinical outcomes. For instance, study done by Ferrie found that the patients receiving greater amount of protein experienced less fatigue, thicker forearm muscle and higher nitrogen balance, but no difference in mortality or length of stay. ${ }^{[2]}$ This was a descriptive study without analysis on the correlation between amount of protein received and the relevant clinical parameters. With the current contradictory study outcomes, an analytical study may be warranted to further explore the actual clinical significance of high protein dose for ICU patients. Since this study was retrospective in nature, important data such as clinical parameters might be missing. To allow complete data collection hence proper analysis, a perspective study would be recommended.

The timing of protein delivery may also influence clinical outcomes. However in this study, protein dose was calculated from the average content received by patients throughout ICU stay. This would result in a lower average for patients achieving full calorie slower, due to reasons such as refeeding or early phase of acute illness. A retrospective study found that higher amount of protein administered on day three to five was associated with higher mortality; while an overall higher protein intake was associated with lower mortality. ${ }^{[2]}$ This may call for exploration on the association among the timing, protein dose and the pertaining clinical outcomes.

\section{CONCLUSION}

Despite the satisfactory results demonstrated by this study, in real-life practice, the unawareness of prescribers towards updated greater protein requirement and the physiological changes especially during acute phase of illness may limit the establishment of adequate protein supply to ICU patients. As persistent proteolysis can cause a series of detrimental outcomes and even death, it is important to review the amount of protein supplied to ICU patients from time to time, especially when adjustment has been made. Meanwhile, more well-designed prospective trials are warranted to assess on the actual clinical significance and benefits from increased protein delivery.

\section{ACKNOWLEDGEMENT}

The authors would like to all the healthcare personnel who assisted with providing complete information of the subjects.

\section{REFERENCES}

1. Singer P, Blaser AR, Berger MM, Alhazzani W, Calder PC, Casaer MP, Hiesmayr M, Mayer K, Montejo JC, Pichard C, Preiser JC, van Zanten ARH, Oczkowski S, Szczeklik W, Bischoff SC. ESPEN guideline on clinical nutrition in the intensive care unit. Clin Nutr. 2019;38(1):48-79. doi: 10.1016/j.clnu.2018.08.037, PMID 30348463.

2. Seres D. Nutrition support in critically ill patients: parenteral nutrition [internet]; February 2019. Upto Date [cited May 5 2019]. Available from: https://www. uptodate.com/contents/nutrition-support-in-critically-ill-patients-parenteralnutrition.

3. What is parenteral nutrition [internet]. American Society for Parenteral and Enteral Nutrition; 2014 [cited May 5 2019]. Available from: http://www.nutritioncare.org/ about_clinical_nutrition/what_is_parenteral_nutrition/.

4. Weijs PJ, Cynober L, DeLegge M, Kreymann G, Wernerman J, Wolfe RR. Proteins and amino acids are fundamental to optimal nutrition support in critically ill patients. Crit Care. 2014;18(6):591. doi: 10.1186/s13054-014-0591-0, PMID 25565377.

5. Homeostasis in Humans: maintaining nitrogen balance in the body - higher [internet]. BBCno Year [cited May 5 2019]. Available from: https://www.bbc.com/ bitesize/guides/zxgmfcw/revision/3.

6. Deer RR, Volpi E. Protein requirements in critically ill older adults. Nutrients. 2018;10(3):378. doi: 10.3390/nu10030378, PMID 29558388.

7. Hoffer LJ, Bistrian BR. Nutrition in critical illness: a current conundrum. F1000Res. 2016;5:2531. doi: 10.12688/f1000research.9278.1, PMID 27803805.

8. Paddon-Jones D, Sheffield-Moore M, Zhang X, Volpi E, Wolf SE, Aarsland A, Ferrando AA, Wolfe RR. Amino acid ingestion improves muscle protein synthesis in the young and elderly. Am J Physiol Endocrinol Metab. 2004;286(3):E321-8. doi: 10.1152/ajpendo.00368.2003.

9. Mulherin DW, Cogle SV. Updates in nutrition support for critically III adult patients. Hosp Pharm. 2017;52(1):17-26. doi: 10.1310/hpj5201-17.

10. Heyland DK, Weijs PJ, Coss-Bu JA, Taylor B, KristofAS, O'Keefe GE, Martindale RG. Protein delivery in the Intensive Care Unit: optimal or suboptimal? Nutr Clin Pract. 2017;32(1_suppl):58S-71S. doi: 10.1177/0884533617691245, PMID 28388372.

11. Kasiske B. Guideline on CKD [internet]; 2014. Kdigo.org. [cited May 15 2019] Available from: https://kdigo.org/wp-content/uploads/2017/04/KDIGO-CKDGuideline-Manila_Kasiske.pdf.

12. Body mass index. BMI foundation [internet]. World Health Organization (WHO); Updated 2020 [cited Dec 24 2020]. Available from: https://www.euro.who.int/ en/health-topics/disease-prevention/nutrition/a-healthy-lifestyle/body-massindex-bmi.

13. Defining adult overweight and obesity [internet]. Centers for Disease Control and Prevention (CDC). Updated 2020 [cited Dec 24 2020]. Available from: https:// www.cdc.gov/obesity/adult/defining.html.

14. Pai MP, Paloucek FP. The origin of the "Ideal" body weight equations. Ann Pharmacother. 2000;34(9):1066-9. doi: 10.1345/aph.19381, PMID 10981254.

15. Bauer LA. Applied clinical pharmacokinetics. New York: McGraw-Hill, Medical Publishing Division; 2001. p. 93-179.

16. Weijs PJ, Stapel SN, de Groot SD, Driessen RH, Jong E, Girbes ARJ, et al. Optimal protein and energy mortality in mechanically ventilated critically ill patients: a prospective observational cohort study. J Parenter Enter Nutr. 2012;36:60-8.

17. Heyland DK, Stapleton R, Compher C. Should we prescribe more protein to critically ill patients? Nutrients. 2018;10(4):462. doi: 10.3390/nu10040462, PMID 29642451.

18. Cano NJ, Aparicio M, Brunori G, Carrero JJ, Cianciaruso B, Fiaccadori E, Lindholm B, Teplan V, Fouque D, Guarnieri G, ESPEN. ESPEN guidelines on parenteral nutrition: adult renal failure. Clin Nutr. 2009;28(4):401-14. doi: 10.1016/j. clnu.2009.05.016, PMID 19535181.

19. Watford M. Glutamine and glutamate: nonessential or essential amino acids? Anim Nutr. 2015;1(3):119-22. doi: 10.1016/j.aninu.2015.08.008, PMID 29767158.

20. Martins P. ? Rev Bras Ter Intensiva. 2016;28(2):100-3. doi: 10.5935/0103507X.20160022, PMID 27410403.

21. Ferrie S, Allman-Farinelli M, Daley M, Smith K. Protein requirements in the critically ill: a randomized controlled trial using parenteral nutrition. JPEN J Parenter Enteral Nutr. 2016;40(6):795-805. doi: 10.1177/0148607115618449, PMID 26635305.

22. Koekkoek WACK, van Setten CHC, Olthof LE, Kars JCNH, van Zanten ARH. Timing of PROTein INtake and clinical outcomes of adult critically ill patients on prolonged mechanical VENTilation: the PROTINVENT retrospective study. Clin Nutr. 2019;38(2):883-90. doi: 10.1016/j.clnu.2018.02.012, PMID 29486907. 